付玉娟,金泉,张志斌,张旭东,白伟桦.东北老工业基地产业结构与用水结构关系一一以辽宁省本溪市为例.生态学报,2021,41(22):9029-9038. Fu Y J, Jin Q, Zhang Z B, Zhang X D, Bai W H. Relationship between industrial structure and water utilization structure of old industry base in northeastern China: A case study of Benxi, Liaoning Province.Acta Ecologica Sinica, 2021,41(22) : 9029-9038.

\title{
东北老工业基地产业结构与用水结构关系 以辽宁省本溪市为例
}

\author{
付玉娟 ${ }^{1}$, 金 泉 ${ }^{1}$, 张志斌 $^{2}$,张旭东 ${ }^{1, *}$, 白伟桦 ${ }^{3}$ \\ 1 沈阳农业大学水利学院, 沈阳 110866 \\ 2 辽宁省本溪市水文局, 本溪 117000 \\ 3 辽宁省河库管理服务中心( 辽宁省水文局),沈阳 110003
}

摘要: 为破解东北经济社会发展受水资源承载力刚性约束的迷局, 以典型老工业基地辽宁本溪市为例,通过产业结构区位熵明 确本溪市各产业在全国的发展水平,采用灰色关联度、结构协调度分析产业结构和用水结构的相关程度和协调程度,并通过结 构偏差系数对各产业间和行业间的协调程度进行对比分析。结果表明: 从 2008-2017 年,本溪市一产发展稳定,二产在经历过 大幅下跌之后缓慢增长, 三产在 2016 年之后成为本溪市的支柱产业; 三大产业比例由 2008 年的 0.06:0.60:0.34 调整为 2017 年 的 0.06:0.44:0.50, 曾经占主导优势的重工业及化工业都呈现下降趋势,产业结构发生转变。三大产业平均用水量比例由 2008 年的 0.39:0.59:0.02 调整为 2017 年的 0.41:0.51:0.07, 总用水量减少了 1/4 以上; 规模以上行业中,大部分行业的用水量随着产 值的增加而增加, 需要进一步转换生产工艺; 产值最高的黑色金属冶炼和压延加工业从水资源高效利用角度可作为大力扶持发 展的产业。行业生产规模比较大的黑色金属矿采选业、医药制造业、非金属矿物制品业和黑色金属冶炼和压延加工业等产业与 用水的结构逐渐朝着均衡的状态发展,仍需要一定时间才能达到协调。

关键词:产业结构;用水结构; 区位熵; 结构协调性; 结构偏差系数

\section{Relationship between industrial structure and water utilization structure of old industry base in northeastern China: A case study of Benxi, Liaoning Province}

\author{
FU Yujuan ${ }^{1}$, JIN Quan ${ }^{1}$, ZHANG Zhibin'², ZHANG Xudong ${ }^{1, *}$, BAI Weihu ${ }^{3}$ \\ 1 College of water conservancy, Shenyang Agricultural University, Shenyang 110866, China \\ 2 Benxi Hydrological Bureau of Liaoning Province, Benxi 117000, China \\ 3 Liaoning River Reservoir Management Service Center, Shenyang 110003, China
}

\begin{abstract}
To clarify the interaction and response relationship between industrial structure and water consumption structure in Benxi City, the location entropy, grey correlation degree, coordination degree of industrial structure and water structure and structural deviation coefficient were analyzed. The results are as follows. From 2008 to 2017, the development of primary industry in Benxi was stable, the secondary industry grew slowly after a sharp decline, and the tertiary industry became the pillar industry of Benxi after 2016. The proportion of industries was adjusted from 0.06:0.60:0.34 in 2008 to $0.06: 0.44: 0.50$ in 2017. Heavy industry and chemical industry, which used to be dominant in the past, showed a downward trend, and the industrial structure has changed. The average water consumption ratio of the three industries was adjusted from 0.39:0.59:0.02 in 2008 to 0.41:0.51:0.07 in 2017 and the total water consumption decreased by more than one fourth. In the industries above designated size, the water consumption of most industries increased with the increase of
\end{abstract}

基金项目:国家自然科学基金项目 (51609137)

收稿日期: 2021-01-05; 接收日期:2021-08-16

* 通讯作者 Corresponding author.E-mail: zxxddd@126.com 
output value, and the production process should be further transformed; Smelting and Pressing of Ferrous Metals, with the highest output value, can be used as an industry to support the development from the perspective of water resources development and utilization. Ferrous Metals Mining and Dressing, Medical and Pharmaceutical Products, Nonmetal Minerals Products and Smelting and Pressing of Ferrous Metals industries with relatively large production scale gradually developed towards a balanced state of water use structure, and it still needs some time to achieve coordination.

Key Words : industrial structure; water utilization structure; location entropy; structural coordination; structural deviation coefficient

随着气候的不断变化,水资源时空分布不均加剧,水资源短缺问题不断恶化,而适应性管理是解决该问题 的关键 ${ }^{[1-2]}$ 。面对日益严峻的水资源问题, 需要以水定产、以水定城, 推动我国经济发展方式的战略转型, 在 实现经济增长的同时减少水资源消耗 ${ }^{[3]}$ 。作为新中国工业的摇篮,东北老工业基地拥有一批为中国工业发 展做出突出贡献的国有企业。但近年来, 国有企业由于活力不足、市场化程度不高、过度依赖资源密集型产业 等问题, 导致东北经济发展一直处于全国劣势地位 ${ }^{[4]}$ 。产业结构转变是经济发展的核心变量, 也是推动经济 发展的本质要求 ${ }^{[5-6]}$ 。产业结构的有效调整能促进经济平稳增长、优化社会整体结构、提高创新效率和科技 水平 ${ }^{[7-8]}$, 因此产业的发展和转型是促进东北老工业基地振兴的核心动力。产业结构及各行业的用水水平决 定了用水结构的构成及数量 ${ }^{[9]}$, 所以产业结构的转变势必会对用水结构产生影响 ${ }^{[10]}$, 而用水结构以及水资源 的供需情况也会制约产业结构的调整。因此产业结构与用水结构之间存在相互影响关系。2011 年, 刘晓霞 等 ${ }^{[11]}$ 在对山西省进行用水结构和产业结构的变动关系研究中, 利用格兰杰因果检验法证实第一产业和第三 产业用水量的变化是引起其产值变化原因,但是第二产业的用水量与产值之间的均衡性却不够稳定。对于各 产业内部用水结构与产业结构的相应关系, 许风由 ${ }^{[12]}$ 、王卉剘 ${ }^{[13]}$ 等分别利用灰色关联度对北京市和北京市 海淀区各产业内部的用水量和产值进行分析，证实了产业结构与用水结构之间是存在一定的响应关系。刘 洋 ${ }^{[14]}$ 等通过产业结构偏水度和用水结构粗放度两个指标证实京津冀地区产业结构和用水结构的发展趋势有 一定差异。2014 年刘轶芳 ${ }^{[15]}$ 等构建了结构偏差系数, 从水资源消耗角度对北京市的产业结构调整进行了评 估。该方法能够更好地分析在产业结构和用水结构调整过程中的不均衡程度, 为地区产业结构和用水结构的 调整提供依据。本文以辽宁省本溪市为研究对象, 对该市的产业结构发展转型状况进行评估,在产业结构调 整变迁背景下, 明晰本溪市近年的经济发展与水资源消耗变化过程, 分析三大产业和产业内部两个层次的产 业结构与用水结构的相互影响及响应关系, 为优化经济结构, 合理配置资源, 实现地区经济持续、高效发展提 供依据。

\section{1 研究区概况与方法}

\section{1 研究区概况}

本溪地处辽东半岛腹地, 全境总面积 $8411.3 \mathrm{~km}^{2}$, 属于长白山余脉, 地形呈 “哑铃” 形, 境内山峦起伏, 森林 繁茂, 有辽宁中部平原天然屏障之称。受地形影响, 本溪市降水量比较充沛, 年平均降水量为 800-1000 mm, 其中一半降水量集中在夏季的 7、8 月份。浅层地下水埋深一般为 $0.6-7.5 \mathrm{~m}$, 主要为第四系孔隙潜水和浅层 承压水。境内有中小河流 200 余条, 分属辽河流域的太子河水系和鸭绿江流域的浑江、叆河水系。太子河作 为本溪市的主要河流, 是本溪市生活用水、农业用水、工业用水和生态用水的主要来源, 但同时也是污水、废水 的最终排放处。太子河流域的平均年径流深度为 $288.1 \mathrm{~mm}$, 多年平均水资源量为 $14.5 \times 10^{8} \mathrm{~m}^{3}$, 开发利用率为 $22.8 \%$ 。

受到地形限制, 本溪市农业种植面积仅占总面积的 $10 \%$ 左右, 但水、土地和林业资源及煤炭、铁矿、石灰 石等矿产资源丰富。本溪的工业总产值占总 GDP 的 $60 \%$ 左右, 二产占比最高达 $80 \%$, 且以钢铁和化学工业发 
展为主。作为典型的东北老工业基地,本溪市的产业结构以重、化工产业为主导, 以服务业发展为辅 ${ }^{[16]}$; 重工 业中原材料工业、基础性产业的发展处在主导地位。近年来,本溪逐步建立了本溪钢铁深加工、南芬铸件、本 溪生物医药和桓仁葡萄酒等 4 个产业集群,产业结构进行了一定的调整。

本文根据本溪市 2008-2017 年《辽宁省统计年鉴》、《本溪市统计年鉴》中的经济发展数据和《本溪统市 水资源公报》中的行业用水数据, 分别对产业结构和用水结构的变化情况进行分析, 利用区位熵对产业结构 的变化进行测定; 利用灰色关联度分析各行业和第二产业规模以上行业的产值和用水量的关联程度, 确定两 者之间的相关程度; 在此基础上利用协调度和结构偏差系数分析两者之间的影响和响应关系。

\section{2 研究方法}

\subsection{1 产业结构区位熵}

在产业结构研究中, 区位熵用来分析区域内要素的分布情况, 也可反映某一产业部门的专业化程度以及 它在当地经济中的地位和作用 ${ }^{[17]}$, 计算方法如下:

$$
L Q_{i j}=\frac{q_{i j} / q_{j}}{q_{j} / q}
$$

式中, $L Q_{i j}$ 是指 $j$ 地区的 $i$ 产业在全国的区位熵; $q_{i j}$ 为 $j$ 地区的第 $i$ 产业的产值; $q_{j}$ 为 $j$ 地区的地区生产总值; $q_{i}$ 指 在全国范围内第 $i$ 产业的产值; $q$ 为国内生产总值。区位熵值越大, 说明在此区域内该产业拥有较高的聚集水 平; 若区位熵大于 1 , 表明该产业在区域的经济发展中有很大优势, 且属于主导产业; 若小于 1 ,则处于劣势。

\subsection{2 灰色关联度}

关联度分析是对两个动态系统的发展态势进行量化比较, 反映相对于始点变化速率的关联程度, 用来衡 量两个系统的动态相似程度 ${ }^{[18-20]}$ 。为了分析产业结构与用水结构之间存在相互联系的程度, 本文利用灰色 关联度的方法对二者间的关联性进行分析,计算方法如下:

$$
\gamma\left(x_{0}, x_{i}\right)=\frac{1}{n} \sum_{k=1}^{n} \frac{\operatorname{minmin}_{s}\left|x_{0}(k)-x_{i}(k)\right|+\mu \operatorname{maxmax}_{i}\left|x_{0}(k)-x_{s}(k)\right|}{\left|x_{0}(k)-x_{i}(k)\right|+\mu \max _{s} \max _{t}\left|x_{0}(k)-x_{s}(k)\right|}
$$

式中, $x_{0} 、 x_{i}$ 为两个不同的因素序列, $\mu$ 为分辨系数, 取 $\mu=0.5$ 。 $\gamma \in(0,1]$, 当 $\gamma$ 越接近 1 , 则表明两个因素的关 联程度越高, 相关性也越好。

\subsection{3 产业结构与用水结构协调度}

产业结构偏水度 $(P)$ 和用水结构粗放度 $(W)$ 分别用来对用水结构和产业结构的状态特征进行描述。产 业结构偏水度能够描述一个城市或一个地区的产业结构偏向高耗水产业的程度 ${ }^{[21]}$; 用水结构粗放度是指用 水结构偏向用水效率较低产业的程度 ${ }^{[22]}$; 协调度则能更精准的描述产业结构与用水结构间的演变过程, 以及 它们之间的均衡性和稳定性 ${ }^{[23]}$ 。计算方法如下:

$$
\begin{aligned}
& P=1-\frac{Y-\frac{1}{N} \sum_{i=1}^{N} Y_{i} i}{\frac{N-1}{N} Y} \\
& W=1-\frac{w-\frac{1}{N} \sum_{i=1}^{N} w_{i} i}{\frac{N-1}{N} w} \\
& H=1-\sqrt{P W}
\end{aligned}
$$

式中, $i$ 表示的是各部门产值或用水量按照从大到小排列后对应的次序; $Y_{i}$ 表示第 $i$ 产业增加值, $Y$ 表示区域地 区生产总值; $w_{i}$ 表示第 $i$ 部门用水量, $w$ 表示区域用水总量; $H$ 为产业结构与用水结构协调度。 $P 、 W 、 H \in(0$, 1 ), 当 $P$ 接近 0 时, 说明产业结构偏向耗水量较低的方向越明显; 当 $W$ 接近 0 时, 表明用水结构越偏向用水效 率较高的产业越明显。当 $H$ 越趋近 1 , 说明产业结构与用水结构越协调。 


\subsection{4 结构偏差系数}

结构偏差系数的概念最先出自何道峰等 ${ }^{[24]}$ 的《就业结构变迁与现代化进程》研究报告中, 刘轶芳 ${ }^{[15]}$ 在 2014 年将此概念运用到产业结构与水资源消耗结构的关系研究中。结构偏差系数是利用各产业产值比例与 用水比例之间的关系, 分析产业结构和用水结构的均衡发展程度。为了分析本溪市各产业和各行业用水结构 的合理程度,在刘轶芳所建立的结构偏差系数计算方法的基础上,确定了本文结构偏差系数的计算方法。该 方法不但用来对比分析三大产业间的产业与用水协调程度, 同时首次用来分析第二产业中各行业间的产业与 用水协调情况。计算公式如下:

$$
\varepsilon_{i j}=\log \left(\frac{w_{i}-p_{j}}{p_{i}-w_{j}}\right) i \neq j
$$

式中, $\varepsilon_{i j}$ 为结构偏差系数, $w_{i} 、 w_{j}$ 为第 $i$ 产业或第 $j$ 产业用水量占总用水量的比例, $p_{i} 、 p_{j}$ 为第 $i$ 产业或第 $j$ 产业 的产值占总产值的比例。当 $\varepsilon_{i j}$ 为正, 表明用水结构存在较大的调整空间; 当 $\varepsilon_{i j}$ 为负, 表明产业结构存在较大 的调整空间; 当 $\varepsilon_{i j}$ 接近 0 时, 表明产业结构与用水结构处于比较平衡的发展状态。

\section{2 结果分析}

2.1 本溪市产业结构及用水结构现状及趋势分析

\subsection{1 产业结构}

根据本溪市 2008-2017 年三大产业的产值和第一、二产业内各行业的产值及其比例绘制其变化趋势图， 见图 1。

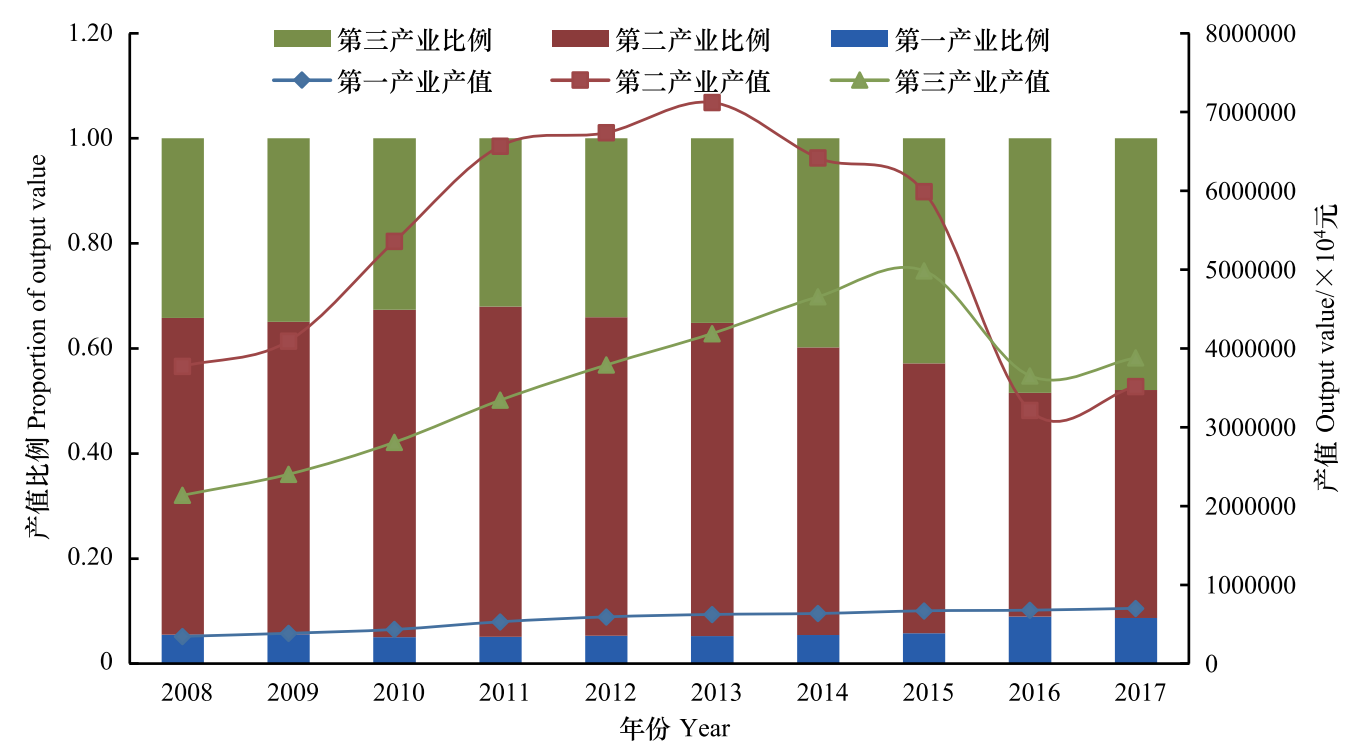

图 1 本溪市 2008一2017 年三大产业结构变化情况

Fig.1 Changes of three marine industrial in Benxi City from 2008 to 2017

从图 1 可以看出,本溪市在 2008-2013 年间生产总产值呈现大幅增长趋势, 2013-2015 年间停止增长, 到 2016 年出现大幅下跌。第一产业整体呈现小幅增加趋势,但占比相对较少,在 $0.05-0.09$ 之间。第二产业 产值与总产值的变化趋势基本一致, 呈现先显著增加后大幅下跌的趋势, 而其比例总体呈现明显的减少趋势, 即第二产业在本溪市的产业比例呈逐年下降趋势; 第二产业的占比在 2012 年之前都稳定在 0.6 左右, 从 2013 年开始明显下降, 到 2018 年降到了 0.44 。第三产业在 2015 年之前呈现线性增加趋势, 在 2015一2016 年也出 现了明显下跌,但跌幅小于第二产业; 其比例则呈现明显的增加趋势, 且其比例在 2015-2016 年间超过了第 二产业,成为本溪市三大产业中的支柱产业。三大产业结构由 2007 年的 6.0:61.9:32.2 调整为 2015 年的 
$5.4: 54.8: 39.8$, 在 2018 年则达到 6.1:45.5:48.5。综上,本溪市三大产业的结构有明显的转换,第二产业的比例 下降明显,第三产业增幅较大。

本溪市的第一产业分为农业、林业、畜牧业、渔业及农林牧渔服务业 4 个部门,各部门产值及其所占比例 见图 2 所示。

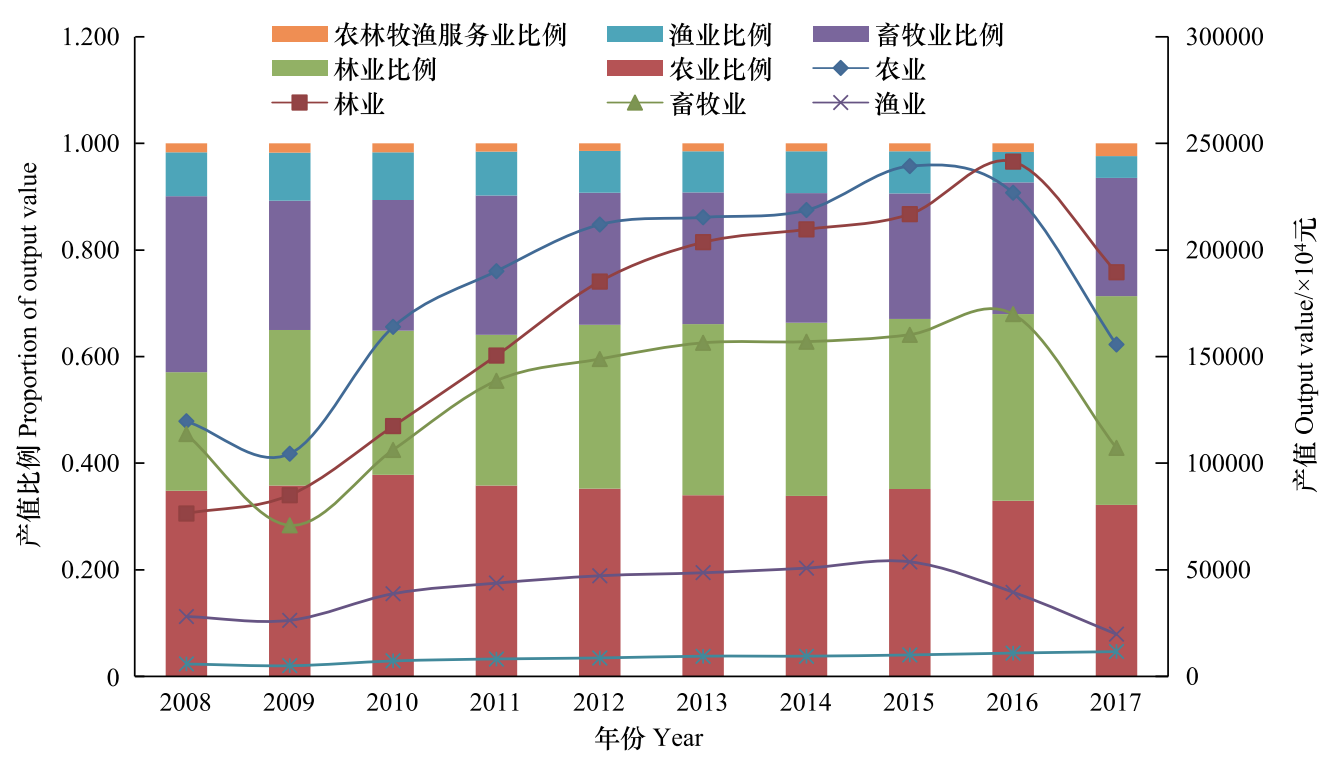

图 2 本溪市 2008一2017 年第一产业各部门产值变化情况

Fig.2 Output value changes of primary industry departments in Benxi City from 2008 to 2017

本溪市农业、林业和畜牧业的产值此 10 年来比较接近,且在 2009-2015 年间表现出相似的发展趋势,但 增速稍有差异,畜牧业、农业和林业在该阶段的年均增速分别为 $14.6 \% 、 14.8 \%$ 和 $16.9 \%$ 。分析期内,林业产值 占比增加近了 0.13 , 林木的栽培、种植及其附属产品的产值逐年增加, 呈现快速发展趋势, 林业替代农业成为 本溪市第一产业的支柱产业。即第一产业中, 畜牧业和农林牧渔服务业产值的比例比较稳定,农业和渔业的 比例有所下降, 仅林业所占比例呈明显的增加趋势。

第二产业所属行业较多,在此选取产值占第二产业比例超过 $1 \%$ 的行业进行分析。各行业的国民经济行 业分类代码见表 1,各行业 2008-2017 年的产值见表 2。

表 1 国民经济行业分类代码

Table 1 Industrial classification code for national economy activities

\begin{tabular}{cl||cl}
\hline 代码 Code & 行业 Industry & 代码 Code & 行业 Industry \\
\hline B08 & 黑色金属矿采选业 & B31 & 黑色金属冶炼和压延加工业 \\
B10 & 非金属矿采选业 & B33 & 金属制品业 \\
B15 & 酒、饮料和精制茶制造业 & B34 & 通用设备制造业 \\
B26 & 化学原料和化学制品制造业 & B35 & 专业设备制造业 \\
B27 & 医药制造业 & B36 & 汽车制造业 \\
B30 & 非金属矿物制品业 & D44 & 电力、热力生产和供应 \\
\hline
\end{tabular}

表 2 中, 本溪市第二产业规模以上行业的产值在这 10 年中发生了剧烈变化,产业结构随之改变。作为支 柱产业 B31 的产值有涨有跌, 且变幅较大, 在 2008-2015 年间年均减少速率为 $11 \%$, 在 2015 年达到最低, 此 后两年虽有大幅增加, 依然是本溪市第二产业的主体, 但没有达到降低前的水平。产业 B08 和 B27 在 20092014 年间获得了迅速的发展, 特别是作为新兴行业和重点扶持行业的 B27 产值的年增速达到了 $36.9 \%$, 这与 本溪市政府转变产业结构的战略导向有非常大的关系。 
表 $22008-2017$ 年第二产业规模以上行业产值 $/\left(10^{8}\right.$ 元 $)$

Table 2 Output value of secondary industry above designated scale from 2008 to 2017

\begin{tabular}{crrrrrrrrrrrr}
\hline 年份 Years & B08 & B10 & B15 & B26 & B27 & B30 & B31 & B33 & B34 & B35 & B36 & D44 \\
\hline 2008 & 97.9 & 3.3 & 4.9 & 17.9 & 9.0 & 30.2 & 692.9 & 9.0 & 10.3 & 5.5 & 12.2 & 14.5 \\
2009 & 82.9 & 5.9 & 7.0 & 19.8 & 11.9 & 22.9 & 830.8 & 12.7 & 15.0 & 2.6 & 16.7 & 8.5 \\
2010 & 1344.5 & 121.8 & 98.4 & 271.6 & 212.9 & 343.6 & 10835.1 & 174.1 & 271.6 & 34.6 & 263.9 & 108.0 \\
2011 & 2212.7 & 200.8 & 115.1 & 250.4 & 922.1 & 455.4 & 13432.6 & 107.9 & 298.3 & 77.9 & 180.7 & 111.2 \\
2012 & 3222.5 & 342.5 & 148.1 & 355.8 & 1195.5 & 654.5 & 13792.1 & 215.6 & 303.2 & 144.9 & 245.3 & 136.5 \\
2013 & 3522.0 & 431.5 & 180.3 & 470.7 & 1773.0 & 735.7 & 14097.2 & 350.2 & 413.2 & 236.1 & 265.2 & 140.1 \\
2014 & 4175.2 & 556.9 & 223.8 & 631.3 & 2083.9 & 892.1 & 12202.2 & 520.5 & 510.2 & 264.5 & 252.1 & 119.2 \\
2015 & 3013.9 & 354.7 & 256.5 & 492.5 & 1698.4 & 629.9 & 8484.3 & 423.5 & 435.3 & 208.2 & 221.3 & 107.6 \\
2016 & 441.4 & 25.3 & 45.8 & 41.2 & 330.4 & 171.1 & 5783.1 & 124.9 & 43.2 & 6.3 & 79.1 & 127.7 \\
2017 & 556.7 & 29.6 & 42.3 & 76.9 & 276.4 & 221.7 & 9815.9 & 179.1 & 48.9 & 22.8 & 94.6 & 128.5 \\
\hline
\end{tabular}

综上, 本溪市第一产业发展稳定,第二产业在经历过大幅下跌之后缓慢增长,第三产业增长迅速, 且逐步 替代第二产业成为本溪市的支柱产业; 第二产业内, 本溪市占主导优势的重工业及化工业都呈现下降趋势, 仅 B27 和 B31 总体呈现上升趋势。因此可以认定本溪市的产业结构发生了一定程度的调整和转型。

\subsection{2 用水结构}

本溪市三大产业用水量变化情况见图 3 所示。

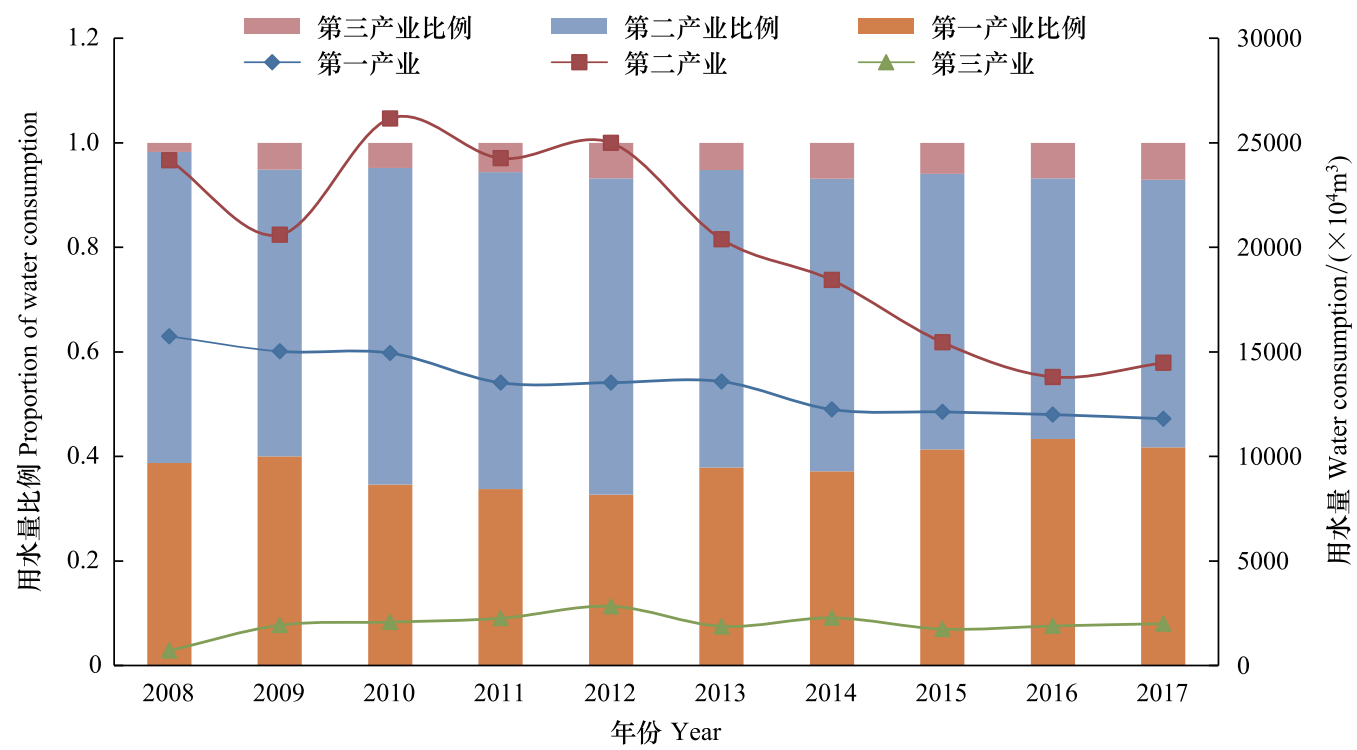

图 3 本溪市 2008一2017 年各产业用水情况

Fig.3 Water consumption of various industries in Benxi City from 2008 to 2017

由图 3 可知,本溪市近十年的用水总量在 2008-2012 年间呈现波动性变化,2012 年之后持续减少。三大 产业中, 第一产业用水量呈稳定的减少趋势, 所占比例由 2009 年的 $40 \%$ 降低到 2012 年的 32.7\%, 后逐渐增 加, 且在 2015 年超过 $40 \%$, 这与总用水量的整体减少趋势有一定的关系。第二产业用水量所占比例最大, 且 变化更为剧烈, 是导致总用水量变化的主导因素。第三产业用水量整体平稳,但由于总用水量减少,其比例有 小幅的上升。与此对应的,全国第一产用水比例近年稳定在 $60 \%$ 以上,二产用水比例在 $20 \%$ 左右。通过对比 可以看出, 本溪市农业用水比例远低于全国整体水平, 而第二产业的用水比例相对较高, 这与本溪市山地多, 农田面积少,雨量相对充沛,第二产业所占比例较高且以重化工业为主等因素有直接关系。

第一产业中,农业年均灌水量为 $1.38 \times 10^{8} \mathrm{~m}^{3}$, 灌溉对象以水田和菜田为主, 是第一产业的主体。本溪市 
年均降雨量达到 800-1000 mm, 基本可以满足森林和牧草的用水需求, 没有人工灌溉补水量, 因此第一产业 内的用水结构不做详细分析。

第二产业规模以上行业的用水量见表 3 所示。

表 $32008-2017$ 年第二产业规模以上行业用水量/ $\left(10^{4} \mathrm{~m}^{3}\right)$

Table 3 Water consumption of secondary industry above designated scale from 2008 to 2017

\begin{tabular}{|c|c|c|c|c|c|c|c|c|c|c|c|c|}
\hline 年份 Years & B08 & $\mathrm{B} 10$ & B15 & B26 & B27 & B30 & B31 & B33 & B34 & B35 & B36 & D44 \\
\hline 2008 & 3310.6 & 11.5 & 45.0 & 257.3 & 32.1 & 557.6 & 11887.5 & 19.0 & 24.7 & 4.0 & 42.2 & 681.9 \\
\hline 2009 & 1383.3 & 11.7 & 76.6 & 374.9 & 38.1 & 477.8 & 15939.1 & 14.9 & 31.0 & 4.6 & 45.5 & 314.3 \\
\hline 2010 & 1065.1 & 12.1 & 75.5 & 182.4 & 65.5 & 315.9 & 18312.5 & 8.3 & 27.7 & 4.3 & 36.7 & 300.5 \\
\hline 2011 & 2057.4 & 2.4 & 41.2 & 164.1 & 63.5 & 405.1 & 16060.9 & 7.9 & 48.5 & 2.4 & 56.9 & 556.9 \\
\hline 2012 & 2573.4 & 3.5 & 50.1 & 351.4 & 118.6 & 404.3 & 12788.1 & 9.3 & 27.7 & 1.5 & 69.5 & 1489.3 \\
\hline 2013 & 2511.3 & 5.6 & 55.0 & 315.4 & 147.7 & 405.9 & 7201.3 & 15.3 & 143.9 & 2.5 & 62.1 & 1441.5 \\
\hline 2014 & 2632.9 & 6.1 & 56.4 & 272.3 & 183.6 & 441.5 & 7012.2 & 23.9 & 148.3 & 2.9 & 45.6 & 1352.4 \\
\hline 2015 & 2278.8 & 6.0 & 61.2 & 261.0 & 206.3 & 432.1 & 5889.5 & 21.4 & 153.0 & 2.9 & 37.1 & 495.7 \\
\hline 2016 & 1785.5 & 3.7 & 56.9 & 250.9 & 150.4 & 367.7 & 5138.6 & 34.0 & 134.2 & 0.4 & 20.1 & 485.1 \\
\hline 2017 & 1462.9 & 4.2 & 57.1 & 308.9 & 153.1 & 342.0 & 5936.9 & 30.9 & 116.3 & 0.4 & 36.8 & 417.9 \\
\hline
\end{tabular}

第二产业中,各行业的用水量因产值的剧烈变化也有一定的震荡, 特别是作为第二产业用水主体的 B31 的用水量在这 10 年中变化剧烈, 2017 年的用水量甚至降低到最大值 2010 年用水量的 1/2 以下。B27、B33 和 B34 这 3 个部门的用水量则存在明显的增加趋势, 特别是作为本溪市新兴产业的 B27 的用水量增幅特别 明显。

综上,本溪市的用水结构表现为第一产业较少, 二产最多,各产业用水量均呈现减少的趋势; 第二产业中, B27、B33 和 B34 的用水量存在明显的增加趋势。

2.2 产业结构区位熵

计算各本溪市 2008一2017 年的地区三大产业的区位熵, 结果见图 4。

受地形限制, 本溪市耕地面积比例仅占总面积的 $8.7 \%$,第一产业区位熵在 2008 年仅 0.54 ; 此后随着林 业经济的快速发展, 区位熵有一定的增加, 但仍明显低 于全国平均水平。本溪市第二产业区位熵始终大于 1 , 拥有较高的聚集水平,即该产业的产值所占比例高于全 国平均水平,对本溪市的经济发展影响较大;但该产业 的区位熵呈现为先缓慢增加后明显减少的发展趋势, 且 越来越接近于 1 ,说明第二产业的规模处于下降态势, 逐步接近全国平均水平,老工业基地的规模优势逐步消 失。第三产业的区位熵在 2008-2013 年间都在 0.75-

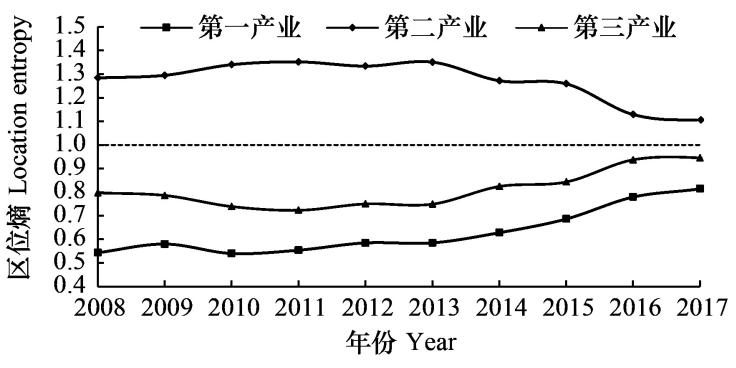

图 4 本溪市 2008一-2017 年三大产业区位熵

Fig.4 Location entropy of three marine industrial of Benxi City from 2008 to 2017 0.8 左右,从 2014 年开始呈现增加态势, 且接近 1 , 即接 近全国整体水平。通过数据分析看出, 本溪市第三产业区位熵的增加与第三产业产值的增加有一定的关系, 但也与第二产业产值大幅下降有直接关系。

综上,本溪市第一、三产业规模低于全国平均水平,但由于林业和第三产业产值的增加, 这两个产业的区 位熵有增加的趋势, 特别是第三产业逐步逼近全国平均水平; 第二产业的区位摘由于传统工业的产值下降而 呈现不断减少趋势, 产业优势不断降低。

2.3 产业结构与用水结构关联度

以 2008-2017 年本溪市各产业的用水量为母因素序列, 对应各产业产值为子因素序列, 利用灰色关联度 
分析两者间的关联程度。结果显示,一、三产业的用水结构与产业结构的关联度为 0.689 ,第二产业为 0.645 。 三大产业的用水量和产值有一定的关联,但关联度不高, 这说明该阶段用水量并没有随着产值的增加而增加, 这与各产业的用水水平和用水效率不断提高有很大关系。

第二产业规模以上产业的产业结构与用水结构关联度的计算结果如表 4 所示。

表 4 本溪市 2008一2017 年规模以上产业产值与用水量关联度

Table 4 Correlation degree of industrial output value and water consumption above designated scale in Benxi City from 2008 to 2017

\begin{tabular}{cc||cc}
\hline $\begin{array}{c}\text { 行业代码 } \\
\text { Industry code }\end{array}$ & $\begin{array}{c}\text { 灰色关联度 } \\
\text { Grey correlation degree }\end{array}$ & $\begin{array}{c}\text { 行业代码 } \\
\text { Industry code }\end{array}$ & $\begin{array}{c}\text { 灰色关联度 } \\
\text { correlation degree }\end{array}$ \\
\hline B08 & 0.78 & B33 & 0.92 \\
B10 & 0.93 & B34 & 0.92 \\
B15 & 0.97 & B35 & 0.97 \\
B26 & 0.95 & B36 & 0.93 \\
B27 & 0.80 & B31 & 0.51 \\
B30 & 0.95 & D44 & 0.85 \\
\hline
\end{tabular}

由表 4 中,本溪市第二产业各行业产值和用水量之间的关联性整体较高,不同行业间差异也比较明显。 12 个行业中, B10、B15、B26、B30、B33、B34、B35 和 B36 等 8 个行业的关联度在 0.9 以上,说明这些行业的产值 和用水量呈一致的变化趋势,需要通过提高生产工艺或引进先进的技术手段,提高用水效率和用水水平,从而 达到降低两者之间关联程度的目的。关联程度较弱的行业,如产值最高的 B31 的用水量和产值的灰色关联 度为 0.509 ,表明这些行业在发展过程中用水量没有随着行业规模的增加而增加,而是用水效率和用水水平不 断提高。从水资源开发利用角度来看,这些产业可作为大力发展的产业。

综上,三大产业的经济与用水量发展的关联度较低,这与各产业用水效率和用水水平不断提高有关;规模 以上行业中, 大部分行业的关联度较高, 用水量随着产值的增加而增加, 需要进一步提高用水水平, 但产值最 高的 B31 的关联度较低,从水资源开发利用角度可作为大力扶持发展的产业。

\section{4 产业结构与用水结构协调性}

对本溪市 2008一-2017 年间三大产业和规模以上行业间的用水结构和产业结构的协调性进行计算, 结果 如图 5 所示。
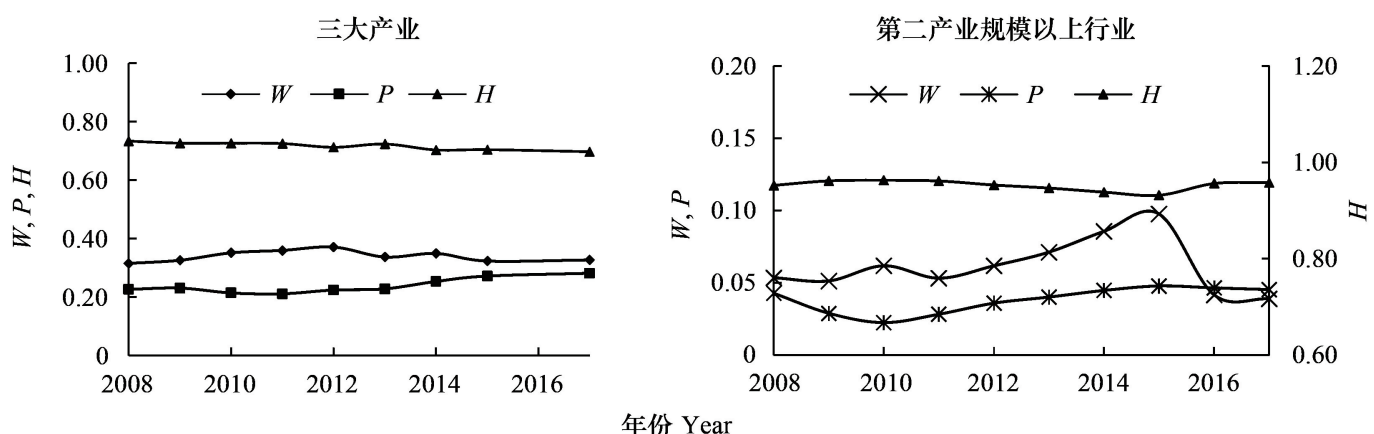

图 5 本溪市 2008 - 2017 年产业结构与用水结构协调度变化

Fig.5 Change of coordination degree between industrial structure and water use structure in Benxi City from 2008 to 2017 $W$ : 用水结构粗放度; $P$ : 产业结构偏水度; $H$ : 产业协调性

图 5 中,三大产业的用水结构粗放度 $W$ 分布在 0.35 左右, 与北京 $(0.4)$ 、天津 $(0.7)$ 和河北 $(0.9)$ 三地相 比 $^{[11]}$, 本溪的用水结构向用水效率较高的产业偏向程度较高, 这主要与本溪市耕地面积小,农业灌溉用水量 较小,而二、三产业用水比例相对较高有关。本溪市产业结构偏水度 $P$ 主要分布在 0.25 左右,与北京 $(0.1)$ 、 天津 $(0.2)$ 和河北 (0.4) 三地相比 ${ }^{[11]}$, 本溪市的产业结构偏向耗水量较低的方向优于河北、低于北京, 与天津 
最为接近, 说明其产业用水效率处于较高的水平。本溪市三大产业协调性 $H$ 分布在 0.7 左右,高于河北 $(0.4)$ 和天津 $(0.5)$, 与北京基本持平 ${ }^{[11]}$ 。即该市的用水结构和产业结构协调性保持稳定, 产业结构和用水结构之 间的协调性处在良好程度。

本溪市第二产业规模以上行业的用水结构粗放度 $W$ 和产业结构偏水度 $P$ 都分布在 0.1 以内,远低于三 大产业粗放度和偏水度,表明本溪市第二产业规模以上行业的用水集中在耗水低和用水效率较高的方向,且 处在较高的水平。第二产业大部分年份协调性数值都在 0.95 以上,说明两个系统之间已经达到了非常高的 协调程度。从变化趋势上来看,本溪市第二产业 $P, W, H$ 的变化不稳定,但从 2016 年之后,趋向耗水低、用水 效率高且协调性更高的方向发展。

综上,本溪市三大产业间粗放度、偏水度和协调度都处在较高水平;第二产业的规模以上行业的粗放度和 偏水度都分布在 0.1 以内,协调度在 0.95 以上,都处于更高的水平,且趋向耗水低、用水效率高且协调性更高 的方向发展。

\section{5 结构偏差系数}

进一步分析本溪市各产业和第二产业规模以上行业间产值占比与用水量占比之间的关系，三大产业间的 结构偏差分析结果见图 6。

图 6 中,一、三产业结构偏差系数均大于 1 , 说明这 两个产业产值对偏差系数的贡献度大于用水的贡献度， 用水效率较低,用水结构存在较大的调整空间,这与第 一产业用水量大但产值小相关。一、二产业的结构偏差 系数在 $0.2-0.4$ 之间,明显低于一、三产业的偏差系数， 说明第一、二产业间用水结构和产业结构发展比较协 调，用水结构仍有一定的调整空间。而二、三产业的偏 差系数逐渐接近 0 , 说明二、三产业的用水结构和产业 结构经不断调整, 逐渐趋于协调状态。发展趋势上, 三 条线趋势线都不同程度的向 0 逼近,说明均向协调的方 向发展。

选取分析期内各行业产值变化比较大具有一定代

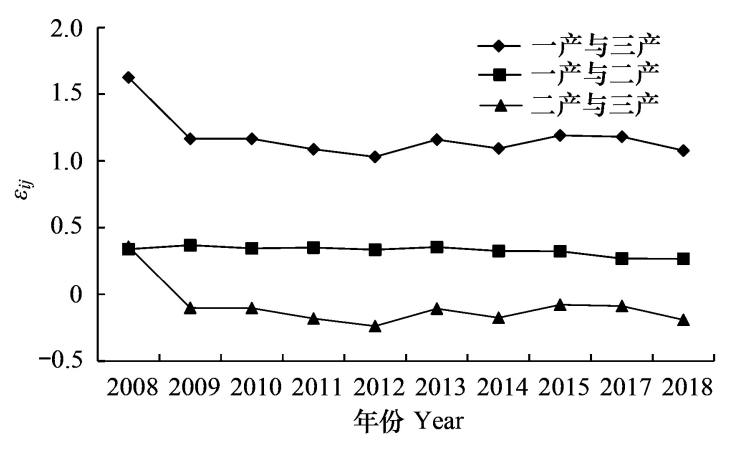

图 6 本溪市 2008一-2017 年三大产业结构偏差系数

Fig.6 Deviation coefficient of three industrial structures in Benxi City from 2008 to 2017 表性的 3 个典型年, 分别为 2008 、2014 和 2017 年, 借此说明对第二产业中规模以上行业的产业结构与用水结 构之间的结构偏差系数。各典型年规模以上行业结构偏差系数的矩阵热图见图 7 。

图 7 中, B08、B10 和 B34 这 3 个产业在经过调整后用水结构与产业结构之间的结构偏差由不均衡状态变
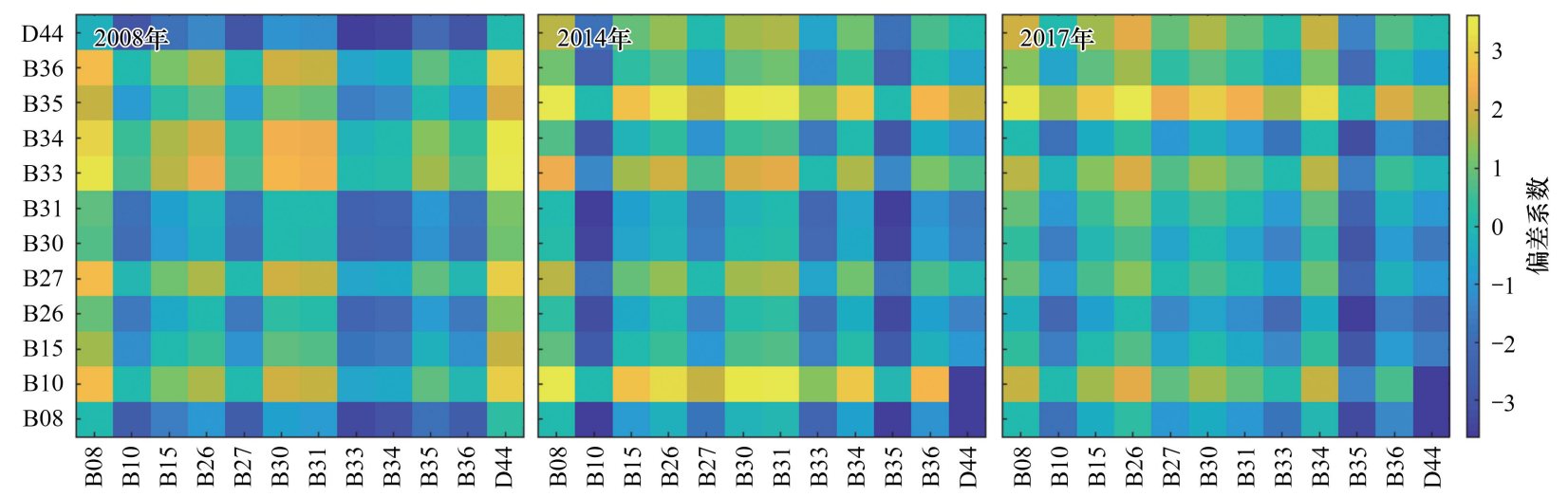

图 7 本溪市典型年规模以上行业产业结构偏差系数

Fig.7 Deviation coefficient of industrial structure above scale in typical years of Benxi City 
到均衡状态的变化比较明显。B10 产业的结构偏差系数变化最明显, 结构偏差系数在 2014 年处在非常不均 衡状态, 经过调整之后, 到 2017 已接近均衡状态。而 B33、B36 和 D44 产业的结构偏差变化幅度较小, 且 D44 产业带来的经济产值与用水量仍然存在较高的不均衡性。B35 的变化与其它产业相差较大, 从 2008 年的接 近均衡发展演变为不均衡状态,产业结构与用水结构之间出现较大偏差。生产规模比较大的 B31、B08、B27、 B30 的结构偏差系数都有减少趋势,其用水结构有较大的调整空间,且趋于协调。

\section{3 结论}

(1) 本溪市第一产业发展稳定,第二产业大幅下跌之后缓慢增长,第三产业增长迅速, 且逐步替代第二产 业成为本溪市的支柱产业; 第二产业中, 仅 B27 和 B31 总体呈现上升趋势, 以往占主导优势的重工业及化工 业都呈现下降趋势。三大产业产值比例由 2008 年的 0.06:0.60:0.34 调整为 2017 年的 0.6:0.44:0.50, 产业结构 发生了一定程度转型; 三大产业用水量比例由 2008 年的 0.39:0.59:0.02 调整为 2017 年的 0.41:0.51:0.07, 总用 水量减少了 $1 / 4$ 以上。

（2）2008-2017 年间,本溪市林业和第三产业产值不断增加，一、三产业的区位熵有增加趋势,特别是第 三产业的发展逐步接近全国平均水平,但一、三产业产值占比仍低于全国平均水平。三大产业经济发展与用 水量发展的关联度较低; 规模以上行业中, 区位熵大于 0.95 的行业用水量随着产值的增加而增加,需要转换 生产工艺,提高用水水平; 产值最高的 B31 从水资源开发利用角度可作为大力扶持发展的产业。

(3) 本溪市三大产业间粗放度、偏水度和协调度都处在较高水平; 一、三产业的用水结构存在非常大的调整 空间,第二产业和第三产业的用水结构和产业结构经不断调整后,逐渐趋于协调状态。第二产业规模以上行业 的粗放度和偏水度处于更高的水平,且趋向耗水低、用水效率高且协调性更高的方向发展。行业生产规模比较 大的 B31、B08、B27、B30 的行业的结构偏差系数都有减少趋势,其用水结构存在较大的调整空间,且趋于协调。

\section{参考文献 (References) :}

[ 1 ] Eliasson J. The rising pressure of global water shortage. Nature, 2015, 517(7532): 6.

[ 2 ] Dong B, Zhang M, Mu H L, Su X M. Study on decoupling analysis between energy consumption and economic growth in Liaoning Province. Energy Policy, 2016, 97 : 414-420.

[ 3 ] 张丽娜, 吴风平, 张陈俊, 庞庆华, 于倩雯. 流域水资源消耗结构与产业结构高级化适配性研究. 系统工程理论与实践, 2020, 40(11)： 3009-3018.

[ 4 ] 姜宏, 徐德斌. 东北老工业基地产业集群低碳发展探析. 税务与经济, 2020, (5)：62-67.

[ 5 ] Chenery H B, Robinson S, Syrquin M. Industrialization and Growth: A Comparative Study. New York: Oxford University Press, 1986.

[ 6 ] 王金玲. 经济新常态下我国产业结构调整效率评价研究 [D]. 太原: 山西财经大学, 2020.

[ 7 ] 曾勉. 利用 FDI 促进四川产业结构调整的策略研究 $[\mathrm{D}]$. 成都: 西南财经大学, 2007.

[8] 干春晖, 郑若谷, 余典范. 中国产业结构变迁对经济增长和波动的影响. 经济研究, 2011, 46(5): 4- 16, 31-31.

[ 9 ] 翟远征, 王金生, 郑洁琼, 狍环. 北京市近 30 年用水结构演变及驱动力. 自然资源学报, 2011，26(4)：635-643.

[10］李欢, 李景保. 近十年来湖南省产业结构与用水结构的耦合协调关系. 水电能源科学, 2019, 37(7): 35-38, 161-161.

[11］刘晓霞, 解建仓. 山西省用水结构与产业结构变动关系. 系统工程, 2011, 29(4)：45-52.

[12] 许风申, 陈林涛, 张春玲, 孙静. 北京市产业结构调整与用水量关系的研究. 中国水利水电科学研究院学报, 2005, 3(4): 258-263.

[13] 王卉䀐, 王妙平. 基于水耗视角的产业结构调整——以北京市海淀北部地区为例. 城市发展研究, 2011，18(3): 58-64.

[14] 刘洋, 李丽娟. 京津冀地区产业结构和用水结构变动关系. 南水北调与水利科技, 2019, 17(2) : 1-9.

[15] 刘轶芳, 刘彦兵, 黄姗姗. 产业结构与水资源消耗结构的关联关系研究. 系统工程理论与实践, 2014, 34(4): 861-869.

[16] 陈妍. 转型期东北地区资源型城市经济一社会一环境系统协调发展机制研究 [D]. 长春: 东北师范大学, 2019.

[17］李学金金, 苗长虹. 城市群产业结构与分工的测度研究一一中原城市群为例. 人文地理, 2006, 21(4) : 25-28, 122- 122.

［18］谭丹, 黄贤金. 我国东、中、西部地区经济发展与碳排放的关联分析及比较. 中国人口・资源与环境, 2008, 18(3) : 54-57.

[19］李健，周慧. 中国碳排放强度与产业结构的关联分析. 中国人口・资源与环境, 2012, 22(1) : 7-14.

[20] Balamurugan S, Gokul C, Abith Tamil Dheen S, Eashwar S J, Arun Kumar N. Application of grey relational analysis in biodiesel production from linseed oil using novel eggshell catalyst. Materials Today: Proceedings, 2021, 45: 1962-1969.

[21］袁少军, 王如松, 胡聑, 孙江. 城市产业结构偏水度评价方法研究. 水利学报, 2004, (10): 43-47.

[22] 蒋桂芹, 于福亮, 赵勇. 区域产业结构与用水结构协调度评价与调控一一以安徽省为例. 水利水电技术, 2012, 43(6): 8-11, 15-15.

[23] Liu X L, Hewings J D G, Chen X K, Wang S Y. A factor decomposing model of water use efficiency at sector level and its application in Beijing. Journal of Systems Science and Complexity, 2016, 29(2): 405-427.

[24] 农业剩余劳动力转移联合课题组. 就业结构变迁与现代化进程一一中国劳动力转移模式的研究. 管理世界, 1990, (4) : 139-151. 